Check for updates

London, UK

Cite this as: BMJ 2020;369:m2439 http://dx.doi.org/10.1136/bmj.m2439 Published: 17 June 2020

\title{
Covid-19: Researchers question policy of closing schools after finding under 20s have low susceptibility to virus
}

\author{
Ingrid Torjesen
}

Children and young people under 20 are half as susceptible to covid-19 and far less likely to experience clinical symptoms than older age groups, a study published in Nature Medicine shows. ${ }^{1}$

The results suggest that interventions targeting children, such as school closures, are therefore likely to have limited impact in controlling spreads of covid-19.

While there have been far fewer cases of covid-19 reported among children during the pandemic it has been unclear whether this is from lower susceptibility to infection or because children are more likely to be asymptomatic or only exhibit minor symptoms.

To gain a better understanding, researchers at the London School of Hygiene and Tropical Medicine applied an age structured mathematical model to epidemic data from Canada, China, Italy, Japan, Singapore, and South Korea to determine the level of susceptibility and clinical symptoms in various age groups.

They found that, following contact with someone infected with covid-19, a person aged under 20 is roughly half as likely to become infected as someone over 20. Relative susceptibility to infection was 0.40 (95\% credible interval: $0.25-0.57$ ) in those aged o to 9 years compared with 0.88 ( $95 \%$ credible interval: 0.70-0.99) in those aged 60 to 69 years.

A "sharp increase" in susceptibility is seen between the ages of 15 and 25, Nicholas Davies, evolutionary biologist and epidemiologist at the London School of Hygiene and Tropical Medicine, told journalists at a press conference on 16 June.

The modelling also showed that younger people who become infected are far less likely to exhibit clinical symptoms with the likelihood increasing gradually with age. The proportion of infected people showing clinical symptoms was $21 \%$ in 10 to 19 year olds (95\% credible interval: $12-31 \%$ ) compared with $69 \%$ (95\% credible interval: $57-82 \%$ ) in people aged over 70 years.

School closures are considered a key intervention for epidemics of respiratory infections, such as influenza, because of the high contact rates between children. To test how effective school closures were likely to be against covid-19, the researchers modelled the impact of a three month closure period on the course of epidemics of covid-19 and influenza in three cities with different populations ages-Milan, Italy (median age of 43 years), Birmingham, UK (median age of 30 years), and Bulawayo, Zimbabwe (median age of 15 years).

School closures decreased the peak incidence by $17-35 \%$ and delayed the peak by $10-89$ days for influenza compared with a $10-19 \%$ peak incidence decrease and a 1-6 day delay of the peak for covid-19. School closures were least effective in populations with lower median ages.

"Whether that is effective enough is very much a policy question," said Davies.

The researchers also simulated covid-19 epidemics in 146 capital cities and found that the number of expected clinical cases varied depending on the median age of the population. The results showed that countries with more young people-generally low and middle income countries-would experience a lower burden of covid-19 cases than high income countries with older populations. However, poorer health outcomes in low and middle income countries would also impact on case numbers, reducing the difference, explained Rosalind Eggo, assistant professor and infectious disease modeller in public health epidemiology at the London School of Hygiene and Tropical Medicine.

1 Davies NG, Klepac P, Liu Y, et al. Age-dependent effects in the transmission and control of covid-19 epidemics. Nat Med 2020 doi: 10.1038/s41591-020-0962-9.

This article is made freely available for use in accordance with BMJ's website terms and conditions for the duration of the covid-19 pandemic or until otherwise determined by BMJ. You may use, download and print the article for any lawful, non-commercial purpose (including text and data mining) provided that all copyright notices and trade marks are retained. 